\title{
¿Habilidades de cambio o cambio de habilidades? "Desarrollar nuestras competencias para adaptarnos $y$ sobrevivir en el puesto de trabajo"
}

Lic. Adm. Felipe SALAZAR ROCHA ${ }^{35}$

\section{RESUMEN:}

Hoy en día las competencias laborales exigen mucho más al profesional. No basta los conocimientos o las destrezas, sino que tenemos que desarrollar "las competencias blandas" a fin de insertarnos apropiadamente en los nuevas retos y demandas de las organizaciones del siglo XXI.

PALABRAS CLAVE: Periodos, Clave Del Futuro, Factor Humano, Adaptación, Divergencia, Investigación.

\section{ABSTRACT:}

Today, business organizations require their employees much more than just professional skills. It's not enough to just have the knowledge or skills. We must all develop "soft skills" to properly insert ourselves in new challenges and demands of current jobs in the organizations of XXI century.

KEYWORDS: Periods, Key to The Future, Human Factor, Adaptation, Divergence, Research.

Si bien es cierto que el Perú en la última década ha tenido un crecimiento sostenido y que se ve reflejado en las inversiones de capital, la infraestructura social, los viajes, el consumo, el surgimiento de nuevas empresas y la construcción de nuevos complejos habitacionales, esto no significa que nuestro futuro este asegurado. 
El peruano, desde un punto de vista empresarial ha sabido salir adelante y ya lo hemos vivido en las duras crisis económicas del pasado. Somos emprendedores, luchadores, idealistas, creativos; deseamos como personas, empresas y país consolidarnos y crecer.

¿Pero, estamos preparados para enfrentar este mundo globalizado que nos reta diariamente?

El estrés y el dinamismo laboral que caracteriza a la sociedad actual, obliga a las empresas a encontrar fórmulas que puedan contribuir a la productividad de sus empleados. La mala noticia es que están escogiendo las opciones incorrectas, o mejor dicho, las menos eficientes.

Probablemente la respuesta está en cada uno de nosotros.

La economía nos enseña que cada cierto tiempo pasamos de periodos de bonanza ha periodos de incertidumbre, por lo que en las actuales coyunturas deberíamos preguntarnos algunos temas claves para planificar nuestro futuro:

¿Quiénes somos? ¿Qué hacemos? ¿Por qué tenemos éxito hoy? ¿Conocemos bien a nuestros clientes, sus necesidades reales? ¿Llegamos a los que queremos llegar? ¿Tenemos una propuesta distinta de nuestros competidores, creando valor? ¿Tendremos una demanda sostenida en el tiempo? ¿Nuestros proveedores nos aseguran calidad y precio? ¿Somos confiables y tenemos una buena reputación? ¿Somos innovadores permanentes? ¿Qué demandas futuras hemos identificado y que nosotros podríamos satisfacer? ¿Hemos aprendido de los errores del pasado o seguimos cayendo en lo mismo? ¿Estamos en condiciones de cambiar de giro si la situación lo amerita? ¿Está mi personal lo suficientemente preparado ante los cambios del entorno?

Estas y otras preguntas más nos deben hacer reflexionar si estamos en el camino correcto para prever las demandas futuras que giraran entorno a tres pilares: desarrollo tecnológico, cambio cultural y cambio en los procesos productivos. Responder a ellas será la diferencia entre el éxito y el fracaso.

Pero, ¿Qué aspectos deben recalcar las empresas hoy?...Las empresas hoy en día se concentran en:

$\checkmark$ Respeto por los individuos, sus derechos y su dignidad.

$\checkmark$ Mediciones agresivas relacionadas con el desempeño, para todos.

$\checkmark$ Fomento de la insatisfacción constructiva.

$\checkmark$ Bajo nivel de temor en la organización.

$\checkmark$ Fracaso visto como proceso de aprendizaje.

$\checkmark$ Utilización de la tecnología como facilitador.

$\checkmark$ Estimulo, reconocimiento y recompensa para los innovadores. 
Seguramente, como ya lo ha sido antes, el factor humano será clave en este proceso. Probablemente los robots reemplazaran el trabajo humano manual pero el pensamiento analítico, reflexivo, sereno, objetivo y concreto será siempre decisión y responsabilidad nuestra.

Solo obtendremos resultados superiores en la medida que nuestros análisis sean divergentes y propendan a una exhaustiva evaluación de todas las variables involucradas. Saquemos de nuestras cabezas y planes, paradigmas que nos frenen en el impulso de experimentar nuevas posibilidades, hagamos de la visión una herramienta que nos conduzca a estrategias ganadoras.

Hoy es fundamental ser capaz de enfrentar los retos que el ambiente laboral nos presenta, como el manejo de las crisis, comunicación efectiva, tolerancia, reenfocar los conflictos a la búsqueda de soluciones para todos, compromiso, motivación permanente, manejo del estrés y del aspecto emocional, etc.

Debemos incluso decir, siendo arriesgado proponer esto, que los empleados deben buscar la felicidad y la organización debe ser el medio para fomentar ello. Un trabajador feliz es más creativo, se adapta mejor al cambio, se entrega más al equipo, aprende mejor, resuelve problemas, se equivoca menos, es más saludable y finalmente será el factor que marque la deferencia con otras organizaciones.

Seamos profesionales con habilidades, destrezas, conocimientos y actitudes realmente únicos. Evitemos que el PRINCIPIO DE PETER ${ }^{36}$ no nos llegue en unos pocos años más.

El temor al futuro es una constante que todos vivimos y pasaremos. La incertidumbre, ingrediente natural de la vida, es también un factor funcional a la misma. Ayuda a crecer, a desarrollar recursos, a forjarse en el imprevisto. Cuando imaginamos que todo lo bueno nos espera en el futuro, empezamos a no soportar nada que ponga a esto en duda. Y si pretendemos vivir como inmortales, nos frustra cada hecho con el que la vida nos recuerda nuestra condición mortal. Muchos deseos hechos, aunque nos enfurezcamos, son parte de la vida. JIGORO KANO, el fundador del judo, nos cuenta esta bella historia, que dio origen a su arte marcial:

"Una noche de invierno había una fuerte tormenta y el observaba como un grande, fuerte y recio roble resistía el viento. A su lado una caña de bambú se inclinaba ante las ráfagas y luego volvía a su posición original. El viento siguió soplando hasta que el árbol grande se derrumbó, mientras que el pequeño y flexible bambú sobrevivió para seguir creciendo..."

Hagamos, entonces, cada uno, nuestra propia reflexión.

36 "Toda persona será promovida hasta alcanzar su nivel de incompetencia." 


\section{REFERENCIAS BIBLIOGRÁFICAS}

1. Bateman, Thomas y Scott SNELL. (2005). Administración. Un nuevo panorama competitivo. ${ }^{a}$. ed. McGraw-Hill Interamericana S.A. 585 páginas.

2. Martínez Selva, José María. (2004). Estrés laboral. Guía para empresarios y empleados. Madrid. Pearson Educación, 222 páginas.

3. YUKL, Gary. (2008). Liderazgo en las organizaciones. Madrid. Pearson Educación, 531 páginas.

4. http://es.wikipedia.org/wiki/Habilidades_gerenciales

5. http://www.degerencia.com/area.php?areaid=1015 